\begin{tabular}{|c|l|}
\hline Title & Characterization of capture cross sections of interface states in dielectric/ll-nitride heterojunction structures \\
\hline Author(s) & Matys, M.; Stoklas, R.; Kuzmik, J.; A damowicz, B.; Y atabe, Z.; Hashizume, T. \\
\hline Citation & $\begin{array}{l}\text { Journal of A pplied Physics, 119(20), 205304 } \\
\text { https://doi.org/L0.1063/1.4952708 }\end{array}$ \\
\hline Issue Date & 2016-05-31 \\
\hline Doc URL & http://hdl.handle.net/2115/65858 \\
\hline Rights & $\begin{array}{l}\text { The following article appeared in J. A ppl. Phys. 119, 205304 (2016) and may be found at } \\
\text { http://dx.doi.org/10.1063/1.4952708. }\end{array}$ \\
\hline Type & article \\
\hline File Information & \begin{tabular}{l}
$1.4952708 . p d f$ \\
\hline
\end{tabular} \\
\hline
\end{tabular}

Instructions for use 


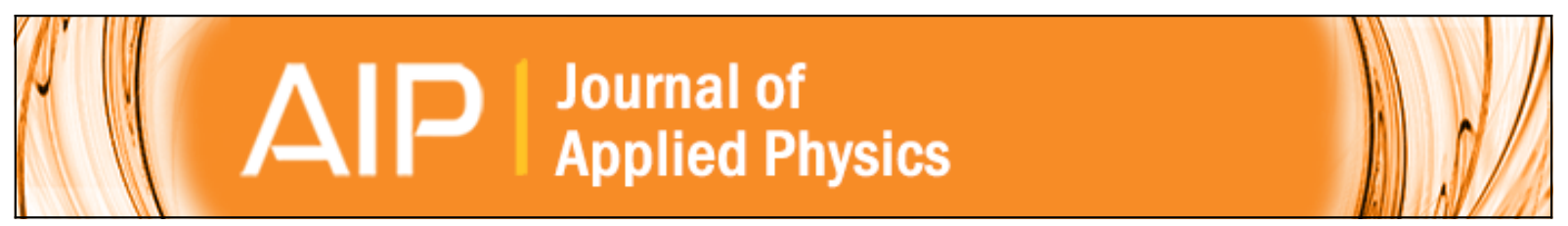

\section{Characterization of capture cross sections of interface states in dielectric/llI-nitride heterojunction structures}

M. Matys, R. Stoklas, J. Kuzmik, B. Adamowicz, Z. Yatabe, and T. Hashizume

Citation: Journal of Applied Physics 119, 205304 (2016); doi: 10.1063/1.4952708

View online: http://dx.doi.org/10.1063/1.4952708

View Table of Contents: http://scitation.aip.org/content/aip/journal/jap/119/20?ver=pdfcov

Published by the AIP Publishing

\section{Articles you may be interested in}

Correlation of interface states/border traps and threshold voltage shift on AIGaN/GaN metal-insulatorsemiconductor high-electron-mobility transistors

Appl. Phys. Lett. 107, 093507 (2015); 10.1063/1.4930076

Defect states characterization of non-annealed and annealed $\mathrm{ZrO} 2 / \mathrm{InAlN} / \mathrm{GaN}$ structures by capacitance measurements

Appl. Phys. Lett. 102, 063502 (2013); 10.1063/1.4792060

Effects of interface states and temperature on the $\mathrm{C}-\mathrm{V}$ behavior of metal/insulator/AIGaN/GaN heterostructure capacitors

J. Appl. Phys. 103, 104510 (2008); 10.1063/1.2924334

Real-space electron transfer in III-nitride metal-oxide-semiconductor-heterojunction structures

Appl. Phys. Lett. 87, 043505 (2005); 10.1063/1.2001745

Surface passivation of GaN and GaN/AIGaN heterostructures by dielectric films and its application to insulatedgate heterostructure transistors

J. Vac. Sci. Technol. B 21, 1828 (2003); 10.1116/1.1585077

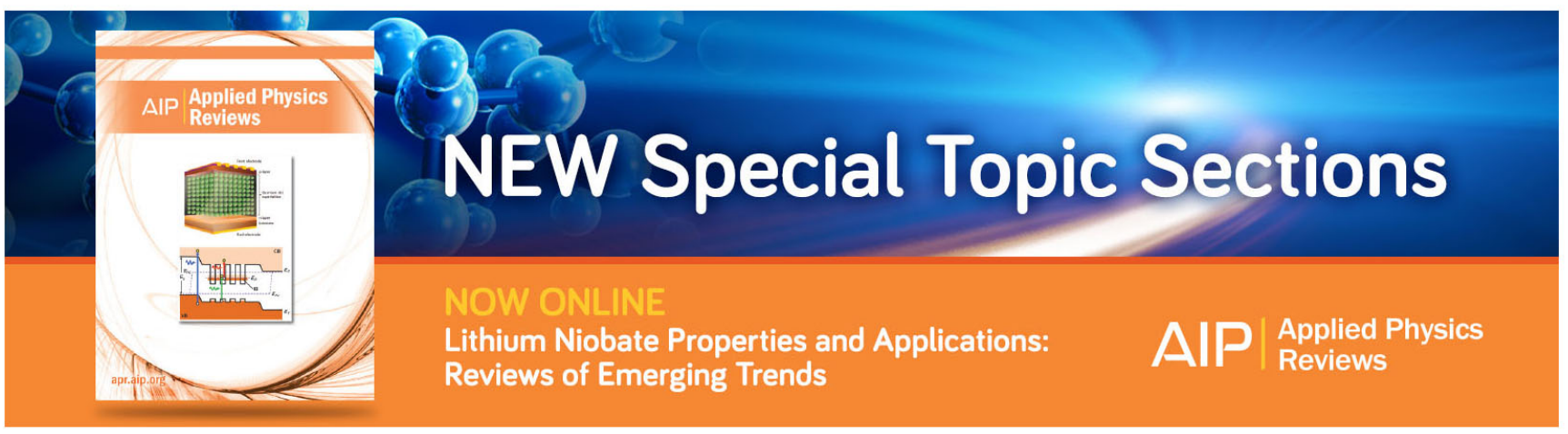




\title{
Characterization of capture cross sections of interface states in dielectric/III-nitride heterojunction structures
}

\author{
M. Matys, ${ }^{1,2}$ R. Stoklas, ${ }^{1,3}$ J. Kuzmik, ${ }^{3}$ B. Adamowicz, ${ }^{2}$ Z. Yatabe, ${ }^{1}$ and T. Hashizume ${ }^{1}$ \\ ${ }^{1}$ Research Center for Integrated Quantum Electronics, Hokkaido University, Kita-13 Nishi-8, Kita-ku, \\ 060-8628 Sapporo, Japan \\ ${ }^{2}$ Surface Physics and Nanostructures Department, Institute of Physics-CND, \\ Silesian University of Technology, Konarskiego 22B, 44-100 Gliwice, Poland \\ ${ }^{3}$ Institute of Electrical Engineering, Slovak Academy of Sciences, Dubravska cesta 9, 84104 Bratislava, \\ Slovak Republic
}

(Received 26 February 2016; accepted 14 May 2016; published online 31 May 2016)

\begin{abstract}
We performed, for the first time, quantitative characterization of electron capture cross sections $\sigma$ of the interface states at dielectric/III-N heterojunction interfaces. We developed a new method, which is based on the photo-assisted capacitance-voltage measurements using photon energies below the semiconductor band gap. The analysis was carried out for $\mathrm{AlGaN} / \mathrm{GaN}$ metal-insulatorsemiconductor heterojunction (MISH) structures with $\mathrm{Al}_{2} \mathrm{O}_{3}, \mathrm{SiO}_{2}$, or $\mathrm{SiN}$ films as insulator deposited on the $\mathrm{AlGaN}$ layers with $\mathrm{Al}$ content $(\mathrm{x})$ varying over a wide range of values. Additionally, we also investigated an $\mathrm{Al}_{2} \mathrm{O}_{3} / \mathrm{InAlN} / \mathrm{GaN}$ MISH structure. Prior to insulator deposition, the AlGaN and InAIN surfaces were subjected to different treatments. We found that $\sigma$ for all these structures lies in the range between $5 \times 10^{-19}$ and $10^{-16} \mathrm{~cm}^{2}$. Furthermore, we revealed that $\sigma$ for dielectric/ $\mathrm{Al}_{x} \mathrm{Ga}_{1-x} \mathrm{~N}$ interfaces increases with increasing $\mathrm{x}$. We showed that both the multiphonon-emission and cascade processes can explain the obtained results. Published by AIP Publishing.

[http://dx.doi.org/10.1063/1.4952708]
\end{abstract}

\section{INTRODUCTION}

$\mathrm{AlGaN}$ and InAlN/GaN high electron mobility transistors (HEMTs) surpass Si devices for high voltage and high speed switching applications due to the exceptional physical properties of nitrides, which include their wide band gaps and stability at high temperatures. ${ }^{1-6}$ It was demonstrated by many groups that GaN-HEMTs with an insulated gate (IG) structure, apart from being necessary for achieving normally off operation, exhibit important advantages over Schottkygate-based GaN-HEMTs such as lower gate leakage current, higher breakdown voltage, better thermal stability of the gate and less current collapse. ${ }^{6-10}$ In order to obtain a good IG structure, suitable insulating materials such as $\mathrm{Al}_{2} \mathrm{O}_{3}, \mathrm{SiO}_{2}$, and $\mathrm{SiN}$ ensuring a large band offset and high permittivity are widely applied. ${ }^{11-13}$ Furthermore, the chosen insulator material should provide a high quality, stable insulator/semiconductor interface with a low density of interface electronic states. Because of the strong impact of these states on the performance and reliability of HEMTs, monitoring the dynamical properties of insulator/semiconductor interfaces is highly desirable.

However, the characterization of interface states is extremely difficult by standard electrical methods for passivated III-N heterojunction structures due to the presence of two interfaces and very long emission time constants from the deep states at room temperature (RT) ${ }^{10-16}$ As a consequence, there is still a lack of understanding of interface state fundamental properties at dielectric/III-N heterojunction interfaces, especially their dynamic trapping/emitting behavior expressed in terms of capture cross sections. Furthermore, it should be noted that, as a matter of fact, there is just only one report ${ }^{17}$ about the values of the capture cross section for dielectric/ III-N heterojunction interfaces. Consequently, in the studies and modeling of the operation of IG-type GaN-based HEMTs, the capture cross section values typical for the $\mathrm{SiO}_{2} / \mathrm{Si}$ interface or bulk defect levels are often inadequately assumed. ${ }^{18-23}$

The aim of the present work is the determination and analysis of the electron capture cross sections $(\sigma)$ of interface states at dielectric/III-N heterojunction interfaces using a newly developed photo-electric method. This method is based on the measurement of the threshold voltage shift $\left(\triangle V_{t h}\right)$ in a capacitance-voltage $(\mathrm{C}-\mathrm{V})$ characteristics before and after illumination using photon energies $\left(E_{p h}\right)$ less than the band gap $\left(E_{g}\right)$ at high temperature $(\mathrm{T})$. In our studies, we used two types of metal-insulator-semiconductor heterojunction (MISH) structures: (i) $\mathrm{AlGaN} / \mathrm{GaN}$ based structures with $\mathrm{Al}_{2} \mathrm{O}_{3}, \mathrm{SiO}_{2}$, and $\mathrm{SiN}$ films as insulator deposited by various techniques on the $\mathrm{Al}_{x} \mathrm{Ga}_{1-x} \mathrm{~N}$ layers with an $\mathrm{Al}$ content varying over a wide range (x) from 0.15 to 0.4 and (ii) an $\mathrm{Al}_{2} \mathrm{O}_{3} / \mathrm{InAlN} / \mathrm{GaN}$ MISH structure. We found that $\sigma$ for the examined structures varied from $5 \times 10^{-19}$ to $10^{-16} \mathrm{~cm}^{2}$. Furthermore, we revealed that $\sigma$ increased with the increasing lattice mismatch in heterostructures. Finally, we demonstrated that both the multiphonon-emission and cascade processes can explain the obtained results.

\section{SAMPLE STRUCTURE AND FABRICATION PROCESS}

Figure 1 shows a schematic illustration of the MISH structures used in this study, i.e., (i) $\mathrm{Al}_{2} \mathrm{O}_{3} / \mathrm{Al}_{0.2} \mathrm{Ga}_{0.8} \mathrm{~N} / \mathrm{GaN}$ with a metal-organic chemical vapor deposition (MOCVD) prepared AlGaN layer (thickness of $34 \mathrm{~nm}$ ) with and without 


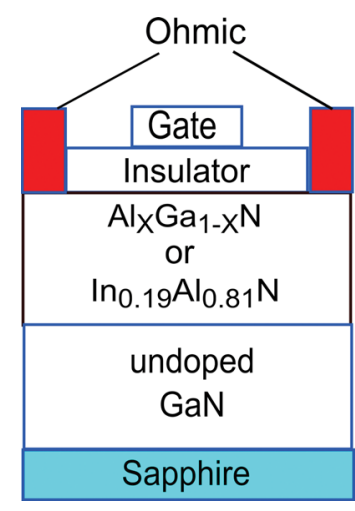

FIG. 1. Scheme of the cross-sectional view of MISH structures used in this study.

inductively coupled plasma (ICP) dry etching (control sample) at $\mathrm{RT} ;{ }^{24}$ (ii) $\mathrm{Al}_{2} \mathrm{O}_{3} / \mathrm{In}_{0.19} \mathrm{Al}_{0.81} \mathrm{~N} / \mathrm{GaN}$ with an MOCVDprepared InAlN layer $\left(12 \mathrm{~nm}\right.$ ); (iii) $\mathrm{SiO}_{2} / \mathrm{Al}_{x} \mathrm{Ga}_{1-x} \mathrm{~N} / \mathrm{GaN}$ with $25 \mathrm{~nm}$ thick modulation doped AlGaN layers $(\mathrm{x}=0.15$, $0.26,0.40$ ); and (iv) $\mathrm{SiN} / \mathrm{Al}_{x} \mathrm{Ga}_{1-x} \mathrm{~N} / \mathrm{GaN}$ with $25 \mathrm{~nm}$ thick modulation doped AlGaN layers $(x=0.15,0.26,0.40)$. The details of the examined structures are summarized in Table I. We used atomic layer deposition (ALD), plasma-enhanced chemical vapor deposition (PECVD), and electron cyclotron resonance chemical vapor deposition (ECR CVD) for deposition of $\mathrm{Al}_{2} \mathrm{O}_{3}, \mathrm{SiO}_{2}$, and $\mathrm{SiN}$ layers, respectively.

All heterojunction samples were cleaned with an HF solution before the insulator deposition in order to mitigate native oxides at the air-exposed AlGaN and InAlN surfaces. The HF treatment was chosen as more efficient in removal of native oxides compared to other treatments using hydrochloric acid or ammonium hydroxide in the case of InAlN and $\mathrm{GaN}^{26,27}$ The applied chemical approach was realized by dipping the sample in the HF solution for $1 \mathrm{~min}$ at RT, then rinsing it in deionized water, followed by a blowing process with pure nitrogen. The X-ray photoelectron spectroscopy study showed that the HF treatment is effective in reducing native oxides at the GaN-based alloys. ${ }^{26,27}$

Ohmic contacts were ring-shaped $\mathrm{Ti} / \mathrm{Al} / \mathrm{Ti} / \mathrm{Au}$ multilayers and gate contacts were either $\mathrm{Al} / \mathrm{Au}$ or $\mathrm{Ni} / \mathrm{Au}$ circles with diameters from 200 to $500 \mu \mathrm{m}$. An ohmic annealing was carried out at $830^{\circ} \mathrm{C}$ for $2 \mathrm{~min}$ in $\mathrm{N}_{2}$. For all types of (i) and (ii) heterostructures, we prepared a $10 \mathrm{~nm}$ thick $\mathrm{SiN}$ protection film deposited by ECR CVD to avoid damages of AlGaN and

TABLE I. The details of examined structures.

\begin{tabular}{lcccc}
\hline \hline Sample & Barrier & $\begin{array}{c}\text { Barrier thickness } \\
(\mathrm{nm})\end{array}$ & $\begin{array}{c}\text { Insulator } \\
\text { (thickness, nm) }\end{array}$ & Remarks \\
\hline 1 & $\mathrm{Al}_{0.2} \mathrm{Ga}_{0.8} \mathrm{~N}$ & 34 & $\mathrm{Al}_{2} \mathrm{O}_{3}(20)$ & w/o ICP \\
2 & $\mathrm{Al}_{0.2} \mathrm{Ga}_{0.8} \mathrm{~N}$ & 27 & $\mathrm{Al}_{2} \mathrm{O}_{3}(20)$ & w/ICP \\
3 & $\mathrm{In}_{0.19} \mathrm{Al}_{0.81} \mathrm{~N}$ & 12 & $\mathrm{Al}_{2} \mathrm{O}_{3}(20)$ & \\
4 & $\mathrm{Al}_{0.15} \mathrm{Ga}_{0.85} \mathrm{~N}$ & 25 & $\mathrm{SiO}_{2}(22)$ & \\
5 & $\mathrm{Al}_{0.26} \mathrm{Ga}_{0.74} \mathrm{~N}$ & 25 & $\mathrm{SiO}_{2}(22)$ & \\
6 & $\mathrm{Al}_{0.40} \mathrm{Ga}_{0.6} \mathrm{~N}$ & 25 & $\mathrm{SiO}_{2}(22)$ & \\
7 & $\mathrm{Al}_{0.15} \mathrm{Ga}_{0.85} \mathrm{~N}$ & 25 & $\mathrm{SiN}_{2}(22)$ & \\
8 & $\mathrm{Al}_{0.26} \mathrm{Ga}_{0.74} \mathrm{~N}$ & 25 & $\mathrm{SiN}(22)$ & \\
9 & $\mathrm{Al}_{0.40} \mathrm{Ga}_{0.6} \mathrm{~N}$ & 25 & $\mathrm{SiN}(22)$ & \\
\hline \hline
\end{tabular}

InAlN surfaces during ohmic contact annealing. ${ }^{16,28}$ After the annealing, the SiN film was removed using buffered HF solution.

\section{EXPERIMENT}

The $\mathrm{C}-\mathrm{V}$ characteristics were measured at $1 \mathrm{MHz}$ by an Agilent 4294A Precision Impedance Analyzer at different temperatures. Figure 2 shows typical $\mathrm{C}-\mathrm{V}$ characteristics of the $\mathrm{Al}_{2} \mathrm{O}_{3} / \mathrm{AlGaN} / \mathrm{GaN}$ structures with and without ICP etching of $\mathrm{AlGaN}$ at RT. For practical processing of fabricating normally off $\mathrm{AlGaN} / \mathrm{GaN}$ HEMTs, a recessed gate structure is often used. The critical processes for fabricating such devices are etching to form the recessed gate region and the subsequent formation of an insulator-semiconductor interface. Since the interface quality markedly affects the transistor performance, it is important to understand the relationship between etching technology and resulting interface electronic properties, including interface cross sections.

We observed the $\mathrm{C}-\mathrm{V}$ curves with two steps which are typical for MISH structures. The nearly flat capacitance at the reverse bias corresponds to the total capacitance of $\mathrm{Al}_{2} \mathrm{O}_{3}$ and AlGaN layers $\left(C_{\text {total }}\right)$ in series, while the constant capacitance at the forward bias is determined by the $\mathrm{Al}_{2} \mathrm{O}_{3}$ oxide capacitance $\left(C_{\mathrm{Al}_{2} \mathrm{O}_{3}}\right)$. When the gate voltage $\left(V_{G}\right)$ approached the threshold voltage $\left(V_{t h}\right)$ in the negative bias range, the capacitance rapidly decreases to nearly zero, signaling the depletion of the two-dimensional electron gas (2DEG) at the AlGaN/ GaN interface. In addition, from Fig. 2, it follows that the sample with ICP etching exhibited increased $C_{\text {total }}$ and significant $V_{\text {th }}$ shift in the $\mathrm{C}-\mathrm{V}$ curve compared with the sample without ICP etching due to the reduced AlGaN layer thickness. It was shown from transmission electron microscopy observation $^{29}$ that the sample without etching exhibited a flat $\mathrm{Al}_{2} \mathrm{O}_{3} / \mathrm{AlGaN}$ interface, indicating the low-energy and layerby-layer characteristics of the ALD process. On the contrary, the ICP etching resulted in the slight roughening of the interface, creating monolayer-level steps at the AlGaN surface. As indicated by the less $\mathrm{C}-\mathrm{V}$ slope in Fig. 2, the ICP-etched

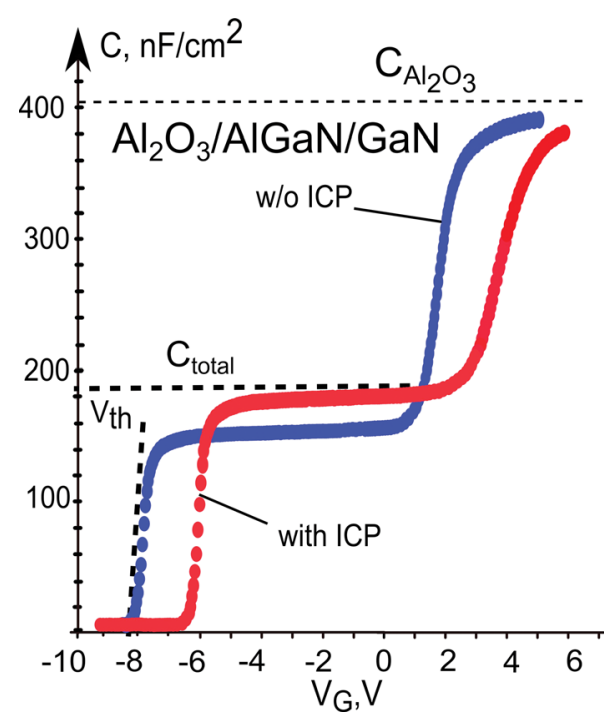

FIG. 2. C-V characteristics of the sample 1 and 2 . 
sample exhibited the higher interface state density probably due to interface disorder. ${ }^{16,24,29}$

The $\triangle V_{t h}$ in $\mathrm{C}-\mathrm{V}$ characteristics was measured in the following manner. The measurement steps and the corresponding band diagrams are schematically shown in Figs. 3 and 4 , respectively. At first, before illumination, we swept the gate voltage from $V_{G}=0 \mathrm{~V}$ to accumulation and then back to depletion to obtain the reference $V_{t h}$ under dark condition. Subsequently, we swept the gate voltage from depletion to accumulation in order to fill the interface states with electrons, as indicated by the broken curve (step 1) in Fig. 3. Then, we swept the gate voltage from accumulation to $V_{G}=0 \mathrm{~V}$ and kept this bias during the time $\left(t_{\text {emit }}\right)$ of about $1 \mathrm{~h}$ (step 2 in Fig. 3). Due to thermal emission for the time of $t_{\text {emit }}$, as shown in Fig. 4(b), the interface states between the conduction band (CB) and energy $E_{t m}$ described by the Shockley-Read-Hall (SRH) statistics are empty of electrons. The $E_{t m}$ value is given as follows:

$$
E_{t m}=k T \ln \left(v_{t h} \sigma N_{C} t_{\text {emit }}\right)
$$

where $v_{t h}$ is the electron thermal velocity and $N_{C}$ is the effective density of states in CB.

Finally, we illuminated the structure by monochromatic light with $E_{p h}<E_{g}$, for $10 \mathrm{~min}$ while keeping $V_{G}=0 \mathrm{~V}$ in order to empty the interface states distributed below $E_{t m}$ of electrons, as shown in Fig. 4(c). Immediately after switching off the light, we restarted the $\mathrm{C}-\mathrm{V}$ sweeping towards depletion under dark condition (step 3 in Fig. 3). As a light source, MAX-302 (ASAHI Spectra) equipped with a xenon lamp and a set of band-pass filters $\left(1.26 \mathrm{eV}<E_{p h}<2.2 \mathrm{eV}\right)$ was used. Under illumination, we clearly observed the parallel $\mathrm{C}$ $\mathrm{V}$ curve shift towards the negative bias direction. The $\Delta V_{t h}$ value was determined as the difference between the $V_{\text {th }}$ after and before illumination. This process was repeated at different $\mathrm{T}$ as well as for different $E_{p h}$, and on this basis, we obtained the $E_{p h}$ and T-dependence of $\triangle V_{t h}$.

\section{METHOD FOR DETERMINATION OF CAPTURE CROSS SECTIONS AND RESULTS}

The main idea of the method developed for the determination of $\sigma$ is based on the estimation of the $E_{t m}$ position from the measurement of light-induced $\triangle V_{t h}$ in the $\mathrm{C}-\mathrm{V}$

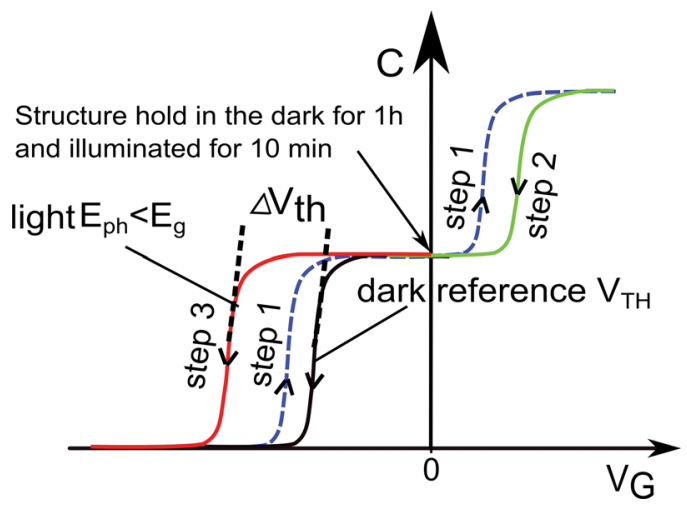

FIG. 3. Schematic illustration of $\triangle V_{t h}$ measurement.

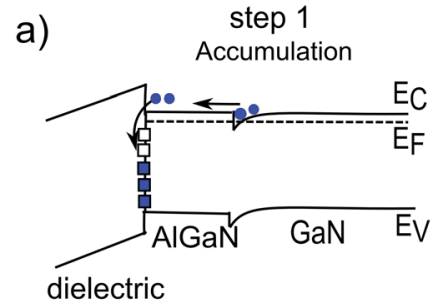

b)
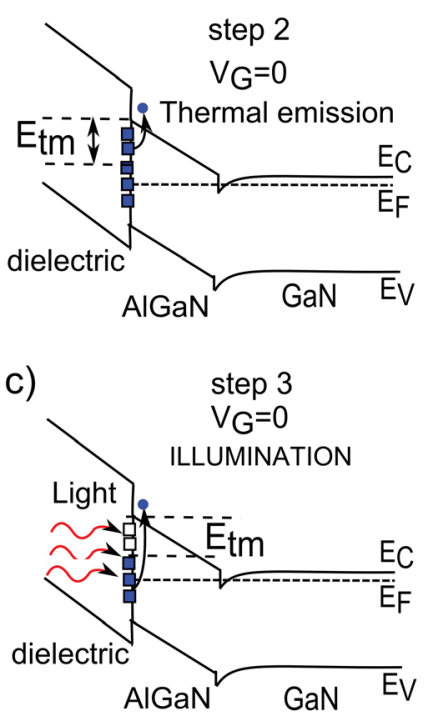

FIG. 4. Schematic band diagrams of an MISH structure illustrating steps of the $\triangle V_{\text {th }}$ measurement; $E_{F}$ is the Fermi level; $E_{F}, E_{V}$, and $E_{C}$ are the band gap edges.

curves at high T. In Fig. 5, we showed the C-V curves before and after illumination with $E_{p h}$ of $1.4 \mathrm{eV}$ and $2.2 \mathrm{eV}$ at RT and $\mathrm{T}=573 \mathrm{~K}$. In Fig. 6, we then summarized the results of light-induced $\triangle V_{t h}$ vs. T. For all the structures, we observed that light-induced $\triangle V_{t h}$ strongly decreased with increasing T. At $\mathrm{T}=573 \mathrm{~K}$, for $E_{p h}=1.4 \mathrm{eV}, \Delta V_{t h}$ is approximately equal to zero, indicating that light has almost no influence on $V_{t h}$ in this particular case.

The fundamental reason of the reduction of $\triangle V_{t h}$ with increasing $\mathrm{T}$ is the changing occupation of the interface states vs. T. For example, during illumination by the photons with energy $E_{p h}$, at given T, the interface states distributed between $E_{p h}$ and $E_{t m}$ become depopulated of electrons, as shown in Fig. 7. This results in the change of the interface charge $\Delta Q_{i t}=q \int_{E_{t m}}^{E_{p h}} D_{i t}(E) d E$ ( $\mathrm{q}$ is the elementary charge) and consequently in the inducing of $\triangle V_{t h}$ equal to

$$
\Delta V_{\text {th }}=\Delta Q_{i t} / C_{\text {total }}
$$

It is obvious that the increasing $\mathrm{T}$ causes decreasing $\triangle Q_{i t}$ due to lowering of $E_{t m}$ and thus reducing $\triangle V_{t h}$. From the fact that for $\mathrm{T}=573 \mathrm{~K}$ and $E_{p h}=1.4 \mathrm{eV}, \triangle V_{t h}$ is approximately equal to zero, we can conclude that $E_{t m} \gtrsim 1.4 \mathrm{eV}$ at this T. On the other hand, based on the approach proposed by Mizue et al., ${ }^{13}$ we determined $D_{i t}(E)$ between 1.2 and $2.2 \mathrm{eV}$ from $E_{p h}$-dependence of $\triangle V_{t h}$ and carried out linear approximation of $D_{i t}(E)$, i.e., $D_{i t}(E)=A+B E$, where $\mathrm{A}$ and $\mathrm{B}$ are the fitting 


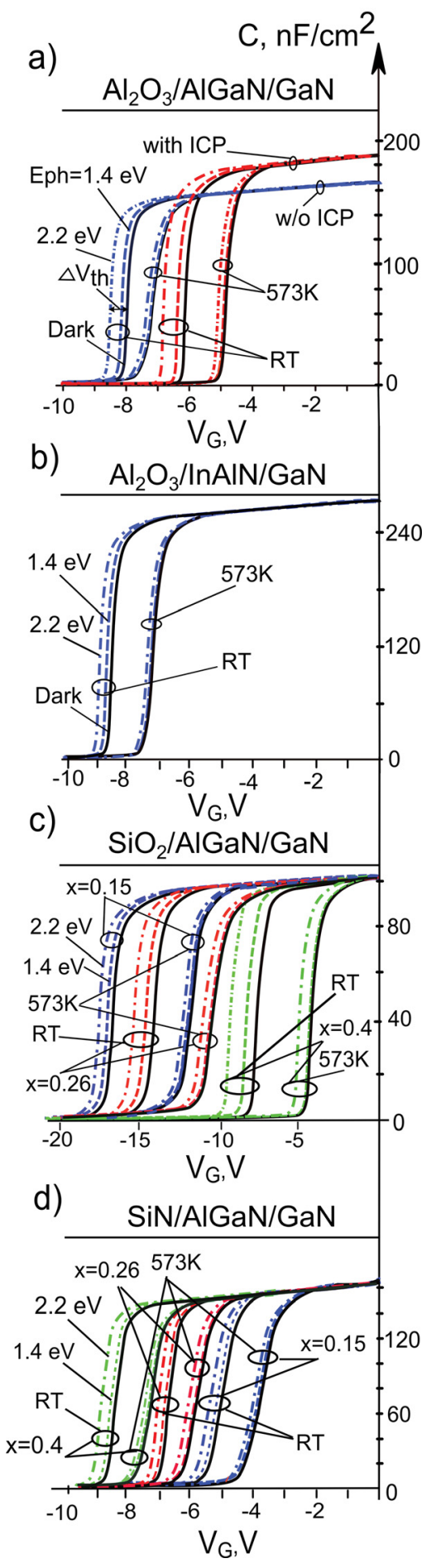

FIG. 5. C-V curves before and after illumination by light with $E_{p h}$ of $1.4 \mathrm{eV}$ and $2.2 \mathrm{eV}$ at $\mathrm{RT}$ and $\mathrm{T}=573 \mathrm{~K}$. The solid lines indicate $\mathrm{C}-\mathrm{V}$ curves measured under dark condition.

coefficients, as shown in Fig. 8. Therefore, using Eq. (2) we can write that $\Delta V_{t h}$ for $E_{p h}=2.2 \mathrm{eV}$ at $\mathrm{T}=573 \mathrm{~K}$ is equal to

$$
\Delta V_{t h}=q\left(A \Delta E+B \frac{(\Delta E)^{2}}{2}\right) / C_{\text {total }},
$$

where $\Delta E=2.2 \mathrm{eV}-E_{t m}$. From Eq. (3), we obtain the following relationship for $E_{t m}$ : a)

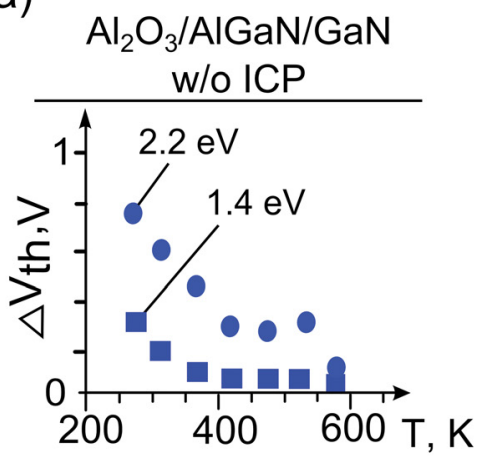

b)

c)
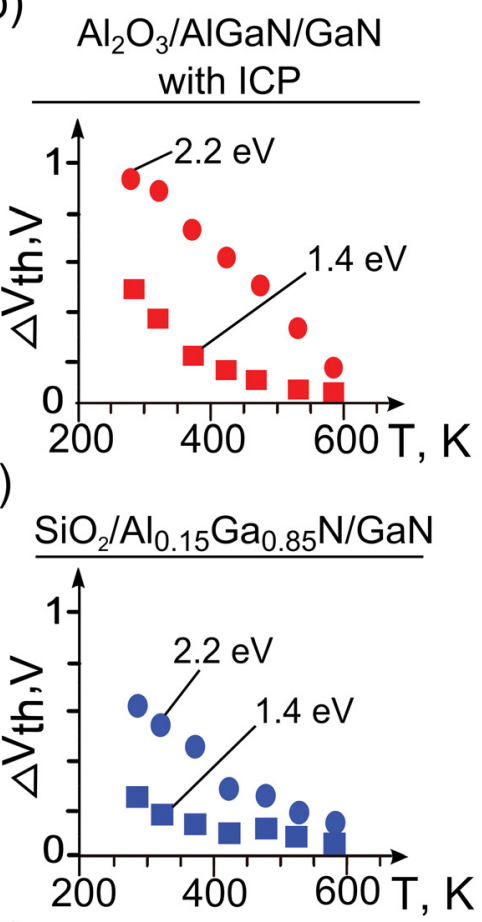

d)

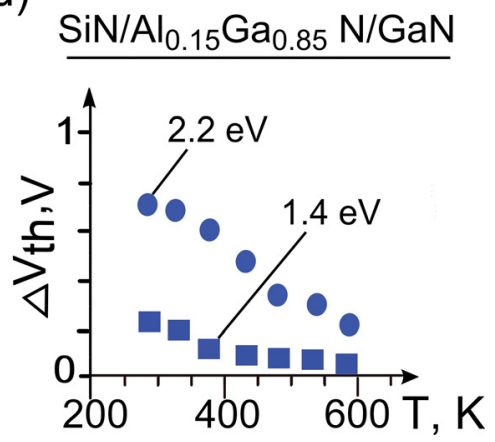

FIG. 6. Light-induced $\triangle V_{t h}$ vs. T for $E_{p h}$ of $1.4 \mathrm{eV}(\square)$ and $2.2 \mathrm{eV}(\bigcirc)$.

$$
E_{t m}=2.2 \mathrm{eV}+\frac{A}{B}-\sqrt{\left(\frac{A}{B}\right)^{2}+2 \frac{C_{t o t a l} \triangle V_{t h}}{q B}} .
$$

Using Eqs. (1) and (4), we determined $\sigma$, which can be interpreted as the average value for the interface states between $\mathrm{CB}$ and near the midgap.

The obtained results of $\sigma$ as a function of the lattice mismatch in the examined $\mathrm{AlGaN} / \mathrm{GaN}$ and InAlN/GaN 


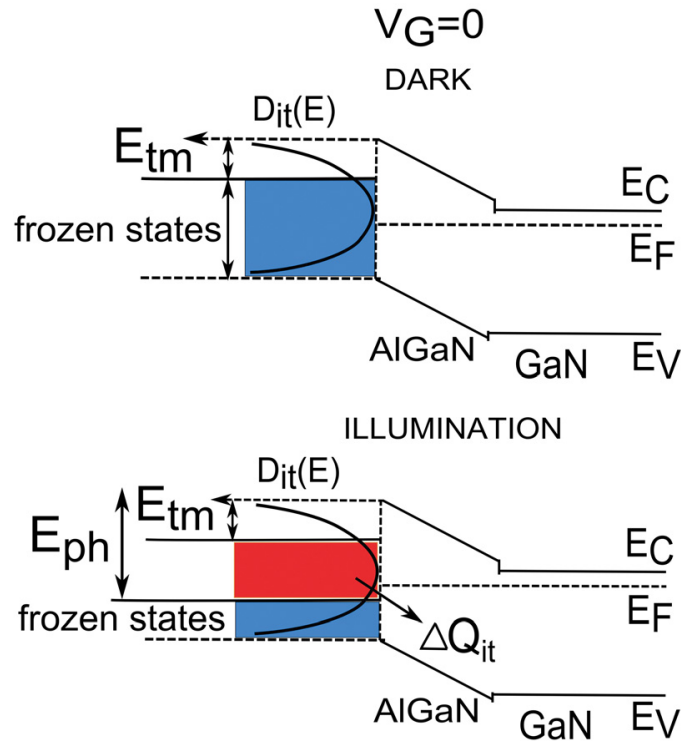

FIG. 7. Schematic illustration of the interface states depopulated by electron transitions under light with photon energy $E_{p h}$ at a given T.

heterostructures are summarized in Fig. 9. The value of $\sigma$ was calculated using the values of $\mathrm{A}$ from $1 \times 10^{11}$ to $5 \times 10^{11} \mathrm{~cm}^{-2} \mathrm{eV}^{-1}$ and $\mathrm{B}$ from $1 \times 10^{11}$ to $5 \times 10^{12}$ $\mathrm{cm}^{-2} \mathrm{eV}^{-2}$. In addition, in order to verify the validity of the proposed method, we performed the calculations of the $\mathrm{C}-\mathrm{V}$ characteristics at RT and $\mathrm{T}=573 \mathrm{~K}$ using the determined $\sigma$ and $D_{i t}(E)$. The calculated $\mathrm{C}-\mathrm{V}$ curves were obtained from a numerical solution of the Poisson's equation by finite element method with Neumann boundary conditions at the interfaces, i.e., insulator/AlGaN and insulator/InAlGaN as well as AlGaN/GaN and InAlGaN/GaN, which were determined by $D_{i t}(E)$ and fixed charge density originating from spontaneous and piezoelectric polarization. ${ }^{14,15}$ The calculation reproduced well the measured $\mathrm{C}-\mathrm{V}$ characteristics, which is an independent confirmation of the reliability of the developed method. It should be noted that in the described method, it is necessary to use a sufficiently high light intensity for the sample illumination in order to obtain full depopulation of the probed interface states corresponding to the saturation of the $\Delta V_{t h}$ and thus avoiding a possible random increase of $\Delta V_{t h}$ vs. T. In addition, in the case of $D_{i t}(E)$

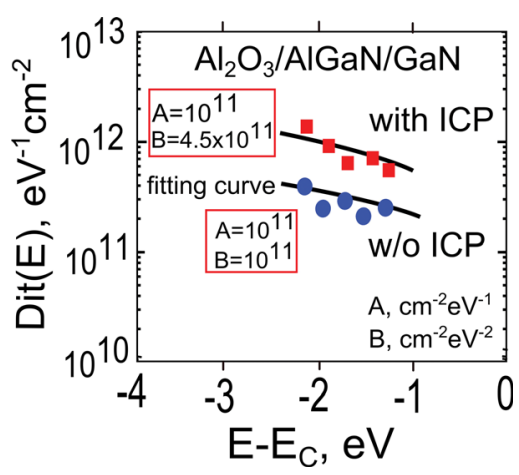

FIG. 8. Illustration of approximation lines of $D_{i t}(E)$ determined using an approach described in Ref. 13. $\bigcirc$ and $\square$ corresponds to sample 1 and sample 2 , respectively.

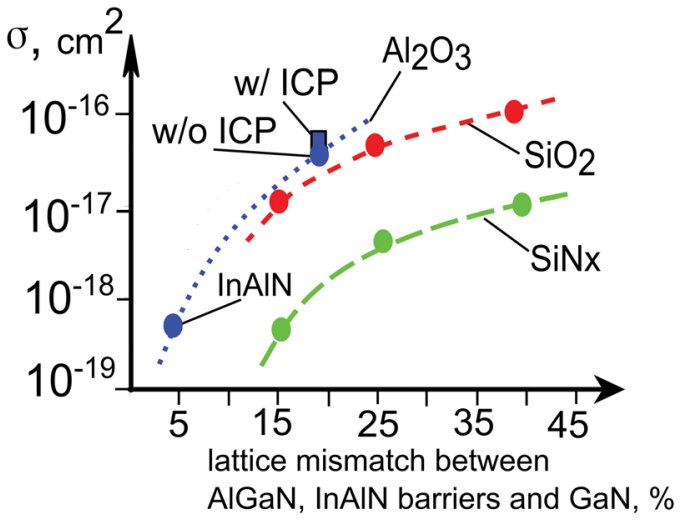

FIG. 9. The obtained $\sigma$ as a function of the lattice mismatch between AlGaN, InAlN barriers, and GaN; dashed lines are shown as guide to the eye.

which cannot be approximated by the straight line, one can use a polynomial fitting.

From the above results (Fig. 9), we can conclude that: (1) $\sigma$ for the interface states at dielectric/III-N heterojunction interfaces is in the range of $5 \times 10^{-19}$ to $10^{-16} \mathrm{~cm}^{2}$, (2) $\sigma$ increases with increasing lattice mismatch in the heterostructures for both ALD- and CVD-prepared insulator layers, and (3) for oxide/III-N heterojunction interfaces takes similar values and almost remains unchanged after the ICP surface treatment. It should be emphasized that such a sensitivity of $\sigma$ on the mismatch variations should be taken into account in the design of GaN-based HEMTs because of the strong impact of $\sigma$ on the device performance.

\section{DISCUSSION}

In general, the non-radiative electron capture and emission from interface states at $\mathrm{SiO}_{2} / \mathrm{Si}$ interface is explained in terms of the multi-phonon emission model introduced by Henry and Lang ${ }^{30-32}$ as well as the cascade mechanism proposed by Lax, ${ }^{33}$ which was later developed by Leningrad (currently Sankt Petersburg) group. ${ }^{34}$ According to the multi-phonon emission model, $\sigma$ is thermally activated and given by

$$
\sigma=\sigma(T=\infty) \exp \left(-\frac{E_{b}}{k T}\right),
$$

where $E_{b}$ is the thermal barrier for capture and can be approximately expressed as the following equation:

$$
E_{b}=\frac{\left(E_{t}-S h \nu\right)^{2}}{4 S h \nu},
$$

where $E_{t}$ is the ionization energy of the state, $h \nu$ is the average phonon energy, and $S$ is the so called Huang-Rhys factor $^{35}$ which is a measure of the strength of electron-phonon coupling. The $E_{b}$ is defined on the configuration diagram (Fig. 10) as being the energy at the crossing of two curves representing the total electronic energy for the initial state before capture and final state after capture.

In the framework of Lax's model, the capture process can be divided into two steps (Fig. 11). At first, electron from $\mathrm{CB}$ is attracted by the long-range Coulomb potential of 


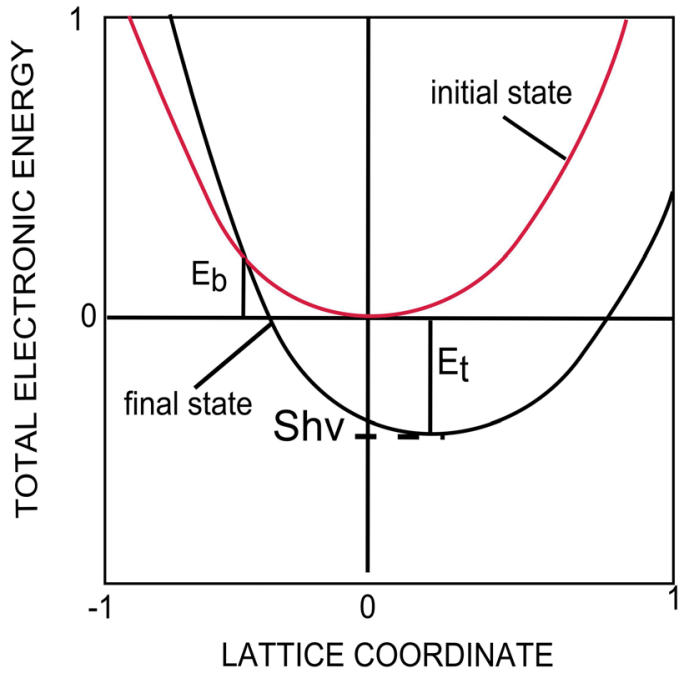

FIG. 10. Configuration coordinate diagram, showing the total electronic energies vs. generalized lattice coordinate for two charged states of a defect, i.e., for the initial state before capture and the final state after capture. $S h \nu$ is the lattice relaxation energy, $E_{t}$ is the ionization energy of the state and $E_{b}$ is the thermal barrier for capture. Both energy and lattice coordinate axes are given in arbitrary units.

the trap. Next, under the assumption that the trap possesses a series of closely separated hydrogen-like excited states, electron jumps to lower states losing its energy by emission of phonons. In both first and second steps, the electron can be regarded as a classical particle. The $\sigma$ value of this process can be approximately expressed as ${ }^{34}$

$$
\sigma=4 \pi\left(\frac{Z q^{2}}{\epsilon m c^{2}}\right)^{3}\left(\frac{m c^{2}}{k T}\right)^{5} \frac{1}{L}
$$

where $Z$ is the atomic number, $q Z$ is the charge of trap, $\epsilon$ is the dielectric constant, $c$ is the velocity of light, $\mathrm{m}$ is the effective mass of electron, $L$ is the mean free path of the electron in the case of collisions with acoustic phonon.

It is evident that both above models can explain the dependencies of $\sigma$ versus mismatch. For example, from Eqs. (5) and (6) it follows that due to the increase of S, $E_{b}$ is reduced and, as a result, $\sigma$ increases. In other words, $\sigma$ is larger for the interface at which the multiphonon process occurs with the stronger lattice distortion (higher Sh $\nu$, Fig. 10). In addition, the multiphonon-emission capture process, related to a lower $E_{b}$, can be enhanced at interfaces with the higher degree of mismatch due to inducing strains resulting in larger $\sigma$. This

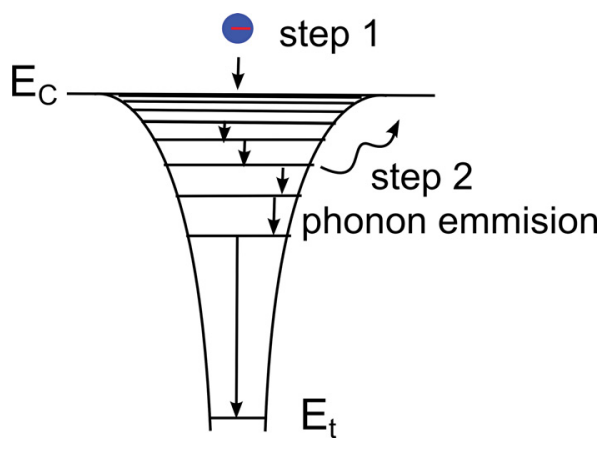

FIG. 11. Schematic illustration of cascade capture process. explanation can be supported by the fact that the examined structures contained thin barriers layers $\left(\mathrm{Al}_{x} \mathrm{Ga}_{1-x} \mathrm{~N}\right.$ and $\left.\mathrm{In}_{x} \mathrm{Al}_{1-x} \mathrm{~N}\right)$ of about $25 \mathrm{~nm}$ in thickness, and thus fully strained for $\mathrm{x}$ up to about 0.4 , according to the literatures. ${ }^{36-39}$ On the contrary, from the theoretical calculation and capacitance/conductivity measurements ${ }^{40}$ it is known that the bulk mobility $(\mu)$ in AlGaN decreases with $\mathrm{x}$ due to alloy-scattering limited. Therefore, because $L \sim \mu$ we expect that $\mathrm{L}$ also deceases with $\mathrm{x}$ and thus $\sigma$ increases with $\mathrm{x}$, according to Eq. (7).

As for the $\mathrm{Al}_{2} \mathrm{O}_{3} / \mathrm{AlGaN}$ interfaces with and without ICP etching of $\mathrm{AlGaN}$, our previous work showed that the ICPetched sample exhibited the higher interface state density probably due to the interface disorder. ${ }^{16,24,29}$ However as shown in Fig. 9, the values of capture cross section remained similar among these samples. This indicates that a lattice distortion due to the heterojunction mismatch dominantly contributes to a mechanism determining the capture cross section. Furthermore, one of the possible reasons for difference observed in the $\sigma$ values between oxides and SiN insulators is the compressive stress, which occurs in the SiN layer more markedly. ${ }^{41}$ This effect can lead to the reduction of the total strain in AlGaN barrier. ${ }^{37}$ Consequently, the multiphonon process can occur with the weaker lattice distortion (lower $\operatorname{Sh} \nu$, Fig. 10) at the SiN/AlGaN interface, resulting in the lower $\sigma$ than those of oxides/AlGaN interfaces.

\section{CONCLUSIONS}

In conclusion, we performed, for the first time, quantitative studies of the carrier capture cross sections of the interface states at dielectric/III-N heterojunction interfaces using a developed photo-electric method. This method is based on the photo-assisted capacitance-voltage measurements using photon energies below the semiconductor band gap. The analysis was carried out for AlGaN/GaN MISH structures with $\mathrm{Al}_{2} \mathrm{O}_{3}, \mathrm{SiO}_{2}$, or $\mathrm{SiN}$ films as insulator deposited on the AlGaN layers with $\mathrm{Al}$ content (x) varying from 0.15 to 0.40 . Additionally, we also investigated an $\mathrm{Al}_{2} \mathrm{O}_{3} / \mathrm{InAlN} / \mathrm{GaN}$ MISH structure. Prior to insulator deposition, the AlGaN and InAlN surfaces were subjected to different treatments. We found that $\sigma$ for all these structures lies in the range of $5 \times 10^{-19}$ to $10^{-16} \mathrm{~cm}^{2}$. We also obtained that $\sigma$ for oxide/ III-N interfaces takes similar values, which remain almost unchanged even after surface treatment. Furthermore, we revealed that $\sigma$ for dielectric/III-N heterojunction interfaces exhibits an increase with the increasing lattice mismatch in heterostructures. We showed that both the multiphononemission and cascade processes can explain the obtained results. These results are crucial to understand the dynamical properties of interface states and should be taken into account in the design of IG-type GaN-based HEMTs.

\section{ACKNOWLEDGMENTS}

This work was partially supported by the National Science Center in Poland within Project No. NCN 515606339 and the Visegrad Group (V4)-Japan Joint Research Program on Highly Safe GaN Metal-Oxide-Semiconductor Transistor Switch. The authors thank Professor M. Akazawa for the Al2O3/InAlN/GaN structure. 
${ }^{1}$ U. K. Mishra, L. Shen, T. E. Kazior, and Y. F. Wu, Proc. IEEE 96, 287 (2008).

${ }^{2}$ M. Kanamura, T. Ohki, T. Kikkawa, K. Imanishi, T. Imada, A. Yamada, and N. Hara, IEEE Electron Device Lett. 31, 189 (2010).

${ }^{3}$ K. Shinohara, D. Regan, Y. Tang, A. Corrion, D. Brown, J. Wong, J. Robinson, H. Fung, A. Schmitz, T. Oh, S. Kim, P. Chen, R. Nagele, A. Margomenos, and M. Micovic, IEEE Trans. Electron Devices 60, 2982 (2013).

${ }^{4}$ D. S. Lee, Z. Liu, and T. Palacios, Jpn. J. Appl. Phys. 53, 100212 (2014).

${ }^{5}$ T. Ueda, M. Ishida, T. Tanaka, and D. Ueda, Jpn. J. Appl. Phys. 53, 100214 (2014).

${ }^{6}$ M. Wang, Y. Wang, C. Zhang, B. Xie, C. P. Wen, J. Wang, Y. Hao, W. Wu, K. J. Chen, and B. Shen, IEEE Trans. Electron Devices 61, 2035 (2014).

${ }^{7}$ T. Hashizume, S. Ootomo, T. Inagaki, and H. Hasegawa, J. Vac. Sci. Technol. B 21, 1828 (2003).

${ }^{8}$ T. Hashizume, S. Ootomo, and H. Hasegawa, Appl. Phys. Lett. 83, 2952 (2003).

${ }^{9}$ D. Gregusova, R. Stoklas, C. Mizue, Y. Hori, J. Novsk, T. Hashizume, and P. Kordos, J. Appl. Phys. 107, 106104 (2010).

${ }^{10}$ Y. Hori, Z. Yatabe, and T. Hashizume, J. Appl. Phys. 114, 244503 (2013).

${ }^{11}$ M. Miczek, C. Mizue, T. Hashizume, and B. Adamowicz, J. Appl. Phys. 103, 104510 (2008)

${ }^{12}$ R. D. Long, C. M. Jackson, J. Yang, A. Hazeghi, C. Hitzman, S. Majety, A. R. Arehart, Y. Nishi, T. P. Ma, S. A. Ringel, and P. C. McIntyre, Appl. Phys. Lett. 103, 201607 (2013).

${ }^{13}$ C. Mizue, Y. Hori, M. Miczek, and T. Hashizume, Jpn. J. Appl. Phys., Part 1 50, 021001 (2011).

${ }^{14}$ M. Matys, B. Adamowicz, and T. Hashizume, Appl. Phys. Lett. 101, 231608 (2012).

${ }^{15}$ M. Matys, B. Adamowicz, Y. Hori, and T. Hashizume, Appl. Phys. Lett. 103, 021603 (2013)

${ }^{16}$ Z. Yatabe, Y. Hori, W. C. Ma, J. T. Asubar, M. Akazawa, T. Sato, and T. Hashizume, Jpn. J. Appl. Phys. 53, 100213 (2014).

${ }^{17}$ B. Gaffey, L. J. Guido, X. W. Wang, and T. P. Ma, IEEE Trans. Electron Devices 48, 458 (2001).

${ }^{18}$ D. Bisi, M. Meneghini, M. Van Hove, D. Marcon, S. Stoffels, T. Wu, S. Decoutere, G. Meneghesso, and E. Zanoni, Phys. Status Solidi A 212, $1122(2015)$.

${ }^{19}$ X. Sun, O. I. Saadat, K. S. Chang-Liao, T. Palacios, S. Cui, and T. P. Ma, Appl. Phys. Lett. 102, 103504 (2013).

${ }^{20}$ P. Kordos, R. Stoklas, D. Gregusova, and J. Novak, Appl. Phys. Lett. 94, 223512 (2009).
${ }^{21}$ M. Fagerlind, F. Allerstam, E. O. Sveinbjornsson, N. Rorsman, A. Kakanakova-Georgieva, A. Lundskog, U. Forsberg, and E. Janzen, J. Appl. Phys. 108, 014508 (2010).

${ }^{22}$ B. Bakeroot, S. You, T.-L. Wu, J. Hu, M. Van Hove, B. De Jaeger, K. Geens, S. Stoffels, and S. Decoutere, Appl. Phys. 116, 134506 (2014).

${ }^{23}$ J. Osvald, R. Stoklas, and P. Kordos, Phys. Status Solidi B 252(5), 996-1000 (2015).

${ }^{24}$ Z. Yatabe, Joel T. Asubar, T. Sato, and T. Hashizume, Phys. Status Solidi A 212(5), 1075-1080 (2015).

${ }^{25}$ M. Akazawa, M. Chiba, and T. Nakano, Appl. Phys. Lett. 102, 231605 (2013).

${ }^{26}$ M. Akazawa, B. Gao, T. Hashizume, M. Hiroki, S. Yamahata, and N. Shigekawa, J. Appl. Phys. 109, 013703 (2011).

${ }^{27}$ M. Akazawa, T. Matsuyama, T. Hashizume, M. Hiroki, S. Yamahata, and N. Shigekawa, Appl. Phys. Lett. 96, 132104 (2010).

${ }^{28}$ Y. Hori, C. Mizue, and T. Hashizume, Jpn. J. Appl. Phys. 49, 080201 (2010).

${ }^{29}$ Z. Yatabe, Y. Hori, S. Kim, and T. Hashizume, Appl. Phys. Express 6, 016502 (2013).

${ }^{30}$ C. H. Henry and D. V. Lang, Phys. Rev. B 15, 989 (1977).

${ }^{31}$ D. V. Lang and C. H. Henry, Phys. Rev. Lett. 35, 1525 (1975).

${ }^{32}$ M. Schulz and N. M. Johnson, Solid State Commun. 25, 481 (1978).

${ }^{33}$ M. Lax, Phys. Rev. 119, 1502 (1960).

${ }^{34}$ V. N. Abakumov, V. I. Perel, and I. N. Yassievich, Sov. Phys. Semicond. 12, 1 (1978)

${ }^{35}$ K. Huang and A. Rhys, Proc. R. Soc. 204, 406 (1950).

${ }^{36}$ E. C. Youn, A. E. Romanov, and J. S. Spec, Appl. Phys. Express 4, 061001 (2011).

${ }^{37}$ B. S. Kang, S. Kim, J. Kim, F. Ren, K. Baik, S. J. Pearton, B. P. Gila, C. R. Abernathy, C.-C. Pan, G.-T. Chen, J.-I. Chyi, V. Chandrasekaran, M. Sheplak, T. Nishida, and S. N. G. Chu, Appl. Phys. Lett. 83, 4845 (2003).

${ }^{38}$ O. Ambacher, B. Foutz, J. Smart, J. R. Shealy, N. G. Weimann, K. Chu, M. Murphy, A. J. Sierakowski, W. J. Schaff, L. F. Eastman, R. Dimitrov, A. Mitchell, and M. Stutzmann, J. Appl. Phys. 87, 334 (2000).

${ }^{39}$ J.-M. Bethoux, P. Vennegues, F. Natali, E. Feltin, O. Tottereau, G. Nataf, P. De Mierry, and F. Semond, J. Appl. Phys. 94, 6499 (2003).

${ }^{40}$ S. Rajan, S. P. DenBaars, U. K. Mishra, H. Xing, and D. Jena, Appl. Phys. Lett. 88, 042103 (2006)

${ }^{41}$ W. Tan, P. Houston, G. Hill, R. Airey, and P. Parbook, J. Electron. Mater. 33, 400 (2004). 